\title{
Priority soil micro-aggregate and mezo-aggregate structure synthesis for humic substances better functioning via Biogeosystem Technique soil processing
}

Chernenko V.V. ${ }^{1}$, Glinushkin A.P. ${ }^{2}$, Zinchenko V.E. ${ }^{3}$, Kalinitchenko V.P. ${ }^{2,4}$, Minkina T.M. ${ }^{5}$, Makarenkov D.A. ${ }^{6}$, Mandzhieva S.S. ${ }^{5}$, Sushkova S.N. ${ }^{5}$, Il'ina L.P. ${ }^{7}$, Motasova E.D. ${ }^{2}$

${ }^{1}$ Russian Research Institute of Viticulture and Winemaking, Novocherkassk, Federal Rostov Agrarian Research Center, Rassvet, Rostov Region, Russia, tchernencko2011@yandex.ru

${ }^{2}$ Russian Research Institute of Phytopathology, Bolschije Wjasjomy, Russia

${ }^{3}$ Federal Rostov Agrarian Research Center, Rassvet, Rostov Region, Russia

${ }^{4}$ Institute of Fertility of Soils of South Russia, Persianovka, Russia

${ }^{5}$ Southern Federal University, Rostov-on-Don, Russia

${ }^{6}$ Institute of Chemical Reagents and High Purity Chemical Substances of National Research

Centre "Kurchatov Institute", Moscow, Russia

${ }^{7}$ Southern Scientific Center of Russian Academy of Sciences, Rostov-on-Don, Russia

Keywords: Biogeosystem Technique, intra-soil milling, soil illuvial horizon micro-aggregate and mezoaggregate structure, humic substances better functioning

doi: 10.36291/HIT.2019.chernenko.108

"Soil organic matter - soil mineral matter - humic substances" interfaces are crucial for soil organic matter pool, soil structure and productivity. Agronomy technical means and technologies for humic substances apply to soil are outdated. The technological platform of land use is imitative and leads to improper humic substances management, and humic substances potential for soil full scale improving is restrained.

Standard soil tillage, as well as reclamation tillage fails to transform the soil aggregate system adverse properties. Copying Nature in standard soil processing system leads to upper soil layer excessive dispersion, dead-end porosity, soil compaction and heavy block structure. In result, soil aggregates composition responsible for the "mineral matter - water - organic matter" interface become deteriorated and in its turn deteriorates humic substances functioning in soil.

For breaking through the fundamental shortcoming of current industrial technological platform in the field of "agrarian soil mineral matter - humic substances" interface and better result of humic substances apply, in the framework of Biogeosystem Technique (BGT*) methodology we propose a transcendental (uncommon for Nature - not fully imitating the natural phenomena) approach to soil ameliorative processing - $\mathrm{BGT}^{\star}$ soil improvement - device and technology for illuvial horizon intra-soil milling. Milling working body is fully immersed into the soil. Transcendental artificial soil weathering is applied - not the soil upper layer, but internal soil illuvial layer. Intra-soil milling of a $20-45 \mathrm{~cm}$ layer is forming the soil illuvial horizon micro- and mezo-aggregate geophysical system structure. Machines were developed, field trials fulfilled.

The "mineral matter - water - organic matter" interfaces become more controllable. Favorable conditions for humic substances soil functioning, rhizosphere and plants growth are creating. 36 years after one-time $20-45 \mathrm{~cm}$ layer intra-soil milling, the soil micro-aggregates prevail, water penetrates the soil freely. This provides the multilevel "soil mineral matter - water - organic matter" interfaces, promotes flocculation of the soil particles and dissolved organic matter. Internal soil geophysical and organic-mineral structure surface become more stable.

The plants consume less energy and water, simultaneously use more nutrients, sequestering more $\mathrm{CO}_{2}$ and releasing more ionized $\mathrm{O}_{2}$ most useful for $\mathrm{CH}_{4}$ and other air pollutants oxidizing and stability of the Earth atmosphere. Soil microbiological process important for soil "mineral matter water - organic matter" stable interfaces and humic substances soil functioning is optimized, C content is increased: in $0-20 \mathrm{~cm}$ layer for $25 \%$, in $20-40 \mathrm{~cm}$ layer for $60 \%$. 